\title{
Advance Use For The NMR Relaxometry To Investigate Reservoir Rocks
}

\author{
AL-Obaidi SH, Patkin AA, Guliaeva NI
}

\begin{abstract}
In this work, the capabilities of the Nuclear magnetic resonance (NMR) method for determining the petrophysical parameters of reservoir rocks were considered. For this purpose, rock samples from several oil fields have been investigated. NMR investigation method was used as one of the rapid methods for assessing the potential properties of reservoir rocks without causing damage to the studied models. It was shown that the results of measurements on the cuttings agree with the results obtained by core samples. It was revealed that this method can be used for quantitative assessment of the content of clay minerals and determination of their type. Moreover, the nature of the dependence of the porosity parameter on the NMR porosity, which satisfies the well-known equations, has been experimentally established.
\end{abstract}

Keywords: Clay minerals, NMR, Porosity, Reservoir rocks, Relaxation time.

*Author for Correspondence E-mail: drsudad@gmail.com

\section{INTRODUCTION}

Petrophysical studies of core samples from oil and gas wells are aimed at assessing hydrocarbon reserves and determining the flow and volumetric properties of reservoir rocks. This task can be effectively solved using the express method of NMR-relaxometry, including directly use at the well $[1,2]$.

The main result of measurements and data processing is the formation porosity; total porosity, effective porosity and porosity associated with clays content [ 3 ].

The relaxation time of the fluid in the pore medium depends on the distance to the boundary with the solid surface (matrix). This allows us to draw a conclusion about the macroscopic distribution of the void space (geometric pore size distribution) [ 4, 5 ]. The formation of void space is influenced by clay content and its type.

To assess the surface effects associated with clay minerals, the results of NMR measurements and resistivity measurements are compared.
These studies are necessary to study the specific surface area of the void space and more accurately assess the permeability of samples using the NMR method [ 6,7$]$.

When studying the petrophysical characteristics of reservoir rocks by NMRrelaxometry, there is no mechanical effect, in contrast to standard research methods, which makes it possible to use samples for further researches.

It is shown, in many works, that the measurements carried out on the core and during its destruction have a high correlation coefficient [ 8,9 ].

The recorded signal does not depend on the rock skeleton, but is determined by the amount and type of fluid contained in the pore space.

It is possible to use the results of the analysis of cuttings by NMR to determine the flowvolumetric characteristics of reservoir rocks $[10,11]$. 


\section{VOLUME CONTENT \& THE TYPE OF CLAY MINERALS}

A new and promising area of NMR research is the assessment of the volumetric content and type of clay minerals. The solution of this problem is considered within the framework of three main types of clay distribution: layered, structural and dispersed [ 12,13 , 14 ]. The latter type can be represented by kaolinite, chlorite and illite. Clay and its type will have a different effect on the reservoir properties, as well as on the NMR signal. The analysis of the capabilities of the NMR relaxometry method for assessing the volumetric content and type of clay minerals is performed.

During the work, more than 200 core samples of wells from four oil fields were examined. The samples are represented by fine- and medium-grained sandstone and fine-coarsegrained siltstone with inclusions of coal, pyrite, less often of siderite and organic substances. The porosity coefficient varied within $5-33 \%$, the permeability coefficient was $0.01-2500 \mathrm{mD}$, and the volumetric clay content was $5-32 \%$.

It is shown that the volume content of clay minerals can be estimated from the relaxation times. At close values of porosity and permeability of the studied samples, the NMR spectrum will be in the region of short times in the case of a larger amount of clay, and with an increase in its fraction, the spectrum will shift.

The different volume content of kaolinite in the clay fraction has a significant effect on the shift of the relaxation time spectrum, while the chlorite content has little effect. This is due to the fact that chlorite lines the pores, in contrast to kaolinite, which is dispersed as discrete particles.

Samples with a predominance of one or another clay mineral are characterized by linear dependences. A strong dependence is observed for the kaolinite component of the clay fraction, and a weak one for the chlorite component. The results were obtained by studying core samples at residual saturation.
To detail the type of clay minerals, the dependence of the relaxation time on the volumetric content of clay minerals was plotted (Fig. 1). For the studied samples with a predominance of kaolinite, the relaxation times are $10-18 \mathrm{~ms}$, with a predominance of chlorite, 2-10 ms. The relaxation time in the vicinity of $10 \mathrm{~ms}$ is characterized by a boundary separating the kaolinite component of the clay fraction from the chlorite one.

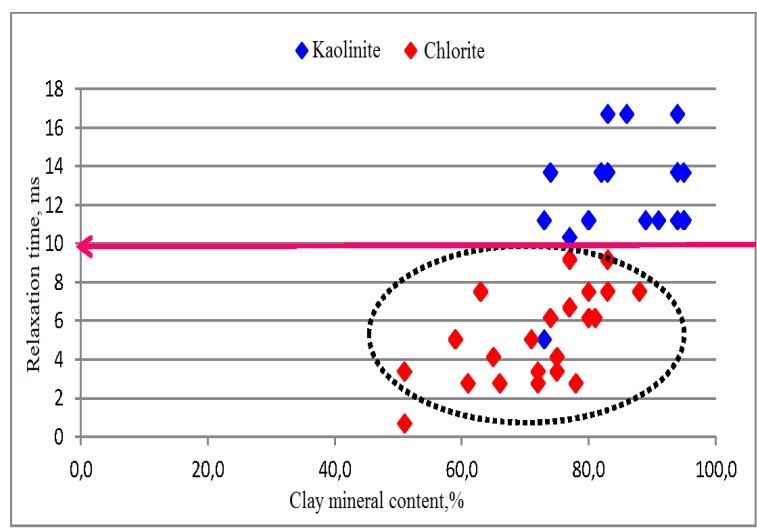

Fig. 1: Dependence of relaxation time on the content of clay minerals

\section{POROSITY PARAMETER $\left(\mathrm{P}_{\mathbf{P}}\right)$}

In this work, an experimental study of the nature of the dependence of the porosity parameter on NMR porosity and its comparative analysis with theoretical dependences has been carried out.

The method of work included the following stages: a) saturate the core samples with a reservoir water model (from 6 to $35 \mathrm{~g} / 1$ ); b) measurements on an NMR relaxometry; c) determination of the electrical resistivity; d) studies by centrifugation (after each speed mode, stages $\mathrm{b}$ and $\mathrm{c}$ were repeated); e) calculation of the porosity parameter.

According to the results of laboratory studies, the relationship between NMR porosity and porosity parameter ( Pp)was revealed (Fig. 2). The obtained dependence has the following form: 


$$
P_{p}=\frac{1,12}{\varphi^{1,81}}
$$

It is consistent with the results of standard studies and satisfies the well-known expressions of the relationship between the parameter and the porosity coefficient.

To compare the revealed experimental relationship with the theoretical dependencies, the formulas proposed in previous works are considered [ $15,16,17,18]$.

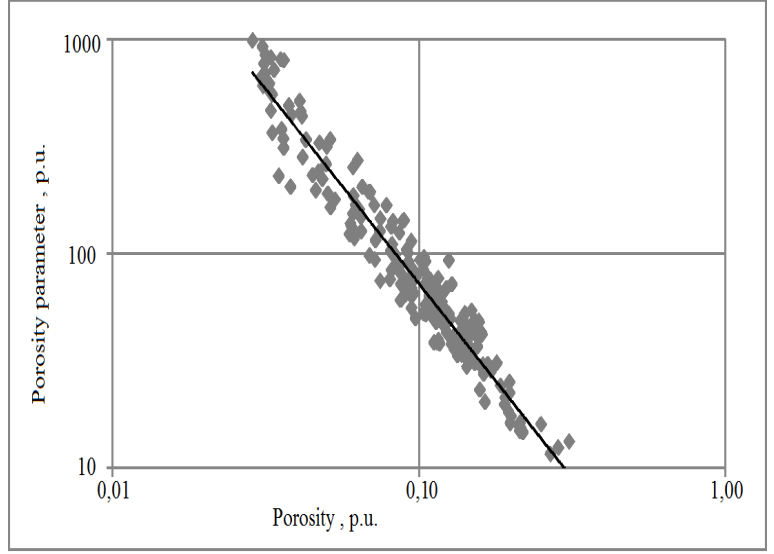

Fig. 2: Relationship between porosity parameter and NMR porosity

To analyze the results obtained, the dependences of the porosity parameter on the NMR porosity calculated using these formulas were constructed.

For the studied samples, the established experimental relationship of these parameters is in good agreement with Timur's formula, which indicates the possibility of estimating the porosity parameter from NMR data using theoretical dependencies.

\section{CONCLUSIONS}

The main results of the work include the following. Laboratory NMR studies of more than 200 core samples from four oil fields have been carried out.

For the studied samples, the convergence of the results of NMR measurements on the core and upon its destruction was established.
It was found that the NMR relaxometry method can be used to assess the quantitative content and type of clay minerals.

An experimental dependence of the porosity parameter and NMR porosity is obtained, which is consistent with the data of standard studies and satisfies the well-known equations.

The NMR relaxometry method can be used as an express method for determining the reservoir properties of reservoir rocks.

\section{REFERENCES}

1. Coates, G.R. and et al. (2000). NMR Logging, Principles \& applications. Hulliburton Energy Services Publishing, Houston, 356.

2. Al-Obaidi, Sudad H., and Guliaeva NI. (2002). "Determination of Flow and Volumetric Properties of Core Samples Using Laboratory NMR Relaxometry." engrXiv, 10.31224/osf.io/t46wj.

3. J. Amix, and et al.(1962). Physics of the oil reservoir. M .: Gostoptekhizdat, 572.

4. Murtsovkin, V.A. and Toporkov, V.G. (2000). New NMR technology for petrophysical studies of core, cuttings and fluids // Karotazhnik, No. 69, 84-97.

5. Al-Obaidi, Sudad H.(1996). "Разработка Методики И Технологии Обработки Данных ГИС И Керна Для Определения Подсчетных Параметров Нефтегазовых Месторождений Ирака : На Прим. Месторождения Вост. Багдад." OSF Preprints, 10.31219/osf.io/f6vka.

6. Mityushin EM and et al.(2002). Method of logging using nuclear magnetic resonance and a device for its implementation // Patent of Russia №2181901.

7. Al-Obaidi, Sudad H. (1996). "Разработка Методики И Технологии Обработки Данных ГИС." OSF Preprints, 10.31219/ osf.io/e68us. 
8. Axelrod, SM and Neretin, VD (1990). Nuclear magnetic resonance in oil and gas geology and geophysics. M., Nedra, 192.

9. Al-Obaidi, Sudad H. and Аль Обейди, Судад Х. (1996).“ ОПРЕДЕЛЕНИЕ ГЛИНИСТОСТИ ПРОДУКТИВНЫХ ПЛАСТОВ МЕСТОРОЖДЕНИЙ НЕФТИ И ГАЗА ВОСТОЧНОГО БАГДАДА.” OSF Preprints, 10.31219/osf.io/dmw9c.

10. Murtsovkin, VA and Toporkov, VG (2000). New NMR technology of petrophysical studies of core, cuttings and fluids // Karotazhnik, No. 69, 84 - 97.4 .

11. Al-Obaidi, Sudad H.(1990). "Comparison of Different Logging Techniques for Porosity Determination to Evaluate Water Saturation." engrXiv, 10.31224/osf.io/fvj9u.

12. Coates, GR and et al.(2000). NMR Logging, Principles \& applications. Hulliburton Energy Services Publishing, Houston, 356.

13. Al-Obaidi, Sudad H.(1998). "Areas of Effective Application of Submersible Centrifugal Pump Installations with and Without a Gas Separator." engrXiv, 10.31224 osf.io/2c $84 \mathrm{~h}$.

14. Mityushin, EM and et al. ( 2002). The first Russian instrument for nuclear magnetic logging using the field of permanent magnets. Geophysics, No. 1 43-50.

15. Al-Obaidi, Sudad H. (1996). "Модификация Уравнения Арчи Для Определения Водонасыщенности Нефтяного Месторождения Восточный Багдад." OSF Preprints, 10.31219/osf.io/tqpn5.

16. Brown R.J.S. and et al. (2001). History of NMR Well Logging. Concepts in Magnetic Resonance (Spatial Thematic Issue), V. 13, No. 6, 335-416.

17. Al-Obaidi, Sudad H.(1999). "Submersible Screw Pumps in Oil Industry."engrXiv, 10.31224/ osf.io/zqu3c.
18. Axelrod, S.M. (1999) . "Petrophysical substantiation of NMR in the field of permanent magnets". Methodology and results of laboratory studies of NMR properties of rocks (according to publications in the American geophysical press): Karotazhnik, no. $59,28-47$.

\section{Cite this Article}

AL-Obaidi SH, Patkin AA, Guliaeva NI. Advance Use For The NMR Relaxometry To Investigate Reservoir Rocks 2003; 2(3): $45-48 p$. 